\title{
Limited technology helps to deliver 'e-Learning' in a developing country
}

\author{
Simon Coelho, Amita Chatterjee \\ (School of Cognitive Science, Jadavpur University, India)
}

\begin{abstract}
The growing use of technology in education can surely be tapped into to help deliver learning, especially in developing countries. No doubt, there are limits placed on the computer-mediated communication that is accessible in these developing countries, yet effective use of cognitive principles in designing the learning package, can help to undoubtedly deliver 'e-Learning'. This pilot study was undertaken to see how 'e-learning' or 'Online' learning $(O N)$, would compare with Face-to-Face learning (F2F). While the numbers that could participate in the ON learning were very small, due to the limited capacity of the computer laboratory that was available, their results nevertheless reflect very positive outcomes. The tools used for presenting the learning material were power point slides which were hyperlinked, not merely for extended explanation, but also for immediate feedback and applauding the efforts of the subjects. The pilot study holds a lot of promise for what limited technology, in 'learning spaces' can help to deliver, when the learner is engaged in the process of constructing knowledge.
\end{abstract}

Keywords: e-learning, cognitive theory, computer-mediated communication, technology in learning.

\section{Introduction}

Today, technology is making inroads in every sphere of daily living, and hence it is but natural, that it can be tapped to making the learning process effective. Besides, the 'digital' generation is more comfortable using the computer and mobile devices than they are in using the 'printed text' for learning. With this in mind, this pilot study tries to explore how 'e-Learning' can help to deliver elementary education in developing countries that are handicapped by limitations of technology.

Currently, there is a healthy tension of what constitutes 'education'. Those for 'progressive education' believe, learning should come through experience rather than the acquisition of information and skills by means of drill and practice [1]. The 'back to basics', advocates complain that kids cannot spell or do simple mathematics and it is time to revert to old-fashioned teaching methods. From the perspective of K-12 schooling, the two views are not exclusive and can be integrated using technology in the interest of the learner [2].

E-Learning is being recognized as having the power to transform the performance, knowledge and skills landscape [3]. It is viewed variously as having the potential to improve the quality of learning, improve access to education and training, reduce the cost of education; and, improve the cost-effectiveness of education [4].

\subsection{Use of technology in learning}

Strongly advocating the use of technology in learning, "We stand at the beginning of a major revolution in the way people learn .... We are moving rapidly toward a future when computers will comprise the dominant delivery system in education for almost all age levels and in most subject areas. Not since the invention of the printing press has a technological device borne such implications for the learning process," [5].

Research studies in education demonstrate that the use of technology, like computers, can help improve students' scores on standardized tests [6], improve students' inventive thinking, for instance in problem solving [7], and improve students' self-concept and motivation [8]. This pilot study is able to show that humancomputer interface, has a positive effect on learning, as shown by pretest and posttest scores.

\subsection{ICT to revolutionize education}

Today, elementary education is looking for ways and means of addressing the needs of students as well as of society. A range of arguments are presented for the transformation of $\mathrm{K}-12$ schooling using information and communications technology (ICT). It has the potential to revolutionize the classroom by facilitating moves from rote learning and shallow coverage of content to the acquisition of such higher-order skills as problem solving, questioning, organizing, evaluating and generating knowledge [9], [10]. ICT can also enable teachers to make presentations using motivating and informative multimedia and facilitate active learning in individuals with different needs, improving classroom teaching. This is of much greater importance in India, with the Right to Education Act, (2009) which makes it mandatory for schools to cater to students with different needs. 


\subsection{At opposite ends of the continuum}

At present in the classrooms, at one end of the continuum, there is didactism, which means to teach or engage the mind of the learner. In many cultures, whether Christian, Islamic or Confucian, the traditional classroom has been teacher dominated. Assuming that educated people and texts hold a large collection of information and skills, teachers have transmitted these to the pupils. This is the 'banking' concept of education, in which the scope of action allowed to the students extended only as far as receiving, filing and storing the deposits [11].

At the other end of the continuum lie such ideas as 'discovery learning' and 'constructivism', with learning perceived as an active process through which learners construct new ideas or concepts based upon their current and past knowledge [12], [13]. Here the teacher's role is to encourage the learners to select and transform information, construct hypotheses, discover principles and make decisions beyond the information given. These ideas resonate with the Socratic maieutics, meaning midwifery, a methodology based upon the belief that due to innate reason, knowledge and understanding are latent in the mind of every human being but need to be brought forth through the proposition of problems and subsequent questioning. This is why our word 'education' derives from the Latin educere, 'to lead out'. It really suggests an interactive learning environment.

\subsection{Difficulty of integrating technology}

Knowledge gaps for integrating technology in education can be classified as first- and second-order barriers [14]. First-order barriers are obstacles that are external to teachers, and include: lack of resources, institution, subject culture and assessment. Second-order barriers are intrinsic to teachers, and pertain to attitudes and beliefs as well as knowledge and skills. The first- and second-order barriers, are inextricably linked, and cannot be taken care of in isolation, for example trying to change the teachers' attitudes and beliefs, may not have the desired effect, if the modes of assessment, are not complementary [15].

\section{Pre-digital perspectives of resources}

In addition to the boundaries defined by their initial design, pre-digital resources were constrained by their static nature [16]. Goals and objectives recognized by administration were typically created or chosen by a designer, teacher, or other external agent. Accountability was likewise external: teachers used resources incrementally and linearly to convey specific content; learners attempted to acquire specified knowledge or skills [17]. This is referred to as a 'banking; model, where the educator's role is to regulate the way the world enters into the students [18].

The dominant educational perspective in the pre-digital age reflected an industrial model of production, which continues to dominate many contemporary classrooms [19]. Accordingly, learning has been managed in controlled environments, with information divided into specific topics. Students demonstrate what they have learned from textbooks or teachers by passing tests and meeting performance criteria. In an effort to address external standards, teachers focus not only on what they present but how they present [20].

\subsection{Emerging perspectives on resources}

Digital resources can be as dynamic and malleable as their creators allow. Multiple resources may be aggregated within a single application, but can be reused in theoretically unlimited combinations by accessing their associated metadata. Compilations of varied but related resources, such as text, video, audio, and graphics related to common learning themes, can be simultaneously gathered across multiple repositories.

Another aspect that differentiates digital from analog resources is the ability to isolate various components to meet specific needs within a particular context. A resource does not simply "tell" in a singular or specific sense but provides information to be engaged and interpreted. Meaning is influenced more by the diversity than the singularity of the perspectives taken. The same resource may support vastly different learning needs. Independent of time or location, individuals can retrieve, evaluate, and determine how or if, to use information [21]. The meaning of a resource is established within the context of its use [22].

\section{Cognitive theory of multimedia learning}

According to cognitive theory of multimedia learning (CTML), meaningful learning is active learning in which the learner possesses and uses a variety of cognitive processes to make sense out of the presented information [23]. The major cognitive processes that lead to meaningful learning include selecting relevant information, organizing that information into coherent representations, and integrating these representations with existing knowledge.

According to CTML, the representation and processing of information in humans is handled cognitively by two separate subsystems: one concerned with verbal materials, and the other concerned with nonverbal materials [24]. Presenting students with dual representations of a causal system, using dual code, that is: verbal and nonverbal promotes deeper learning than presenting students with only one representation [25]. For the 
dual-code hypothesis to apply, the information contained in both codes should not be redundant, and the two codes should be integrated so that students are not forced to split their attention between the two codes [26], [27].

\subsection{Pace and control by learner}

\section{What computer-mediated communication offers the learners}

Most researchers in the area of computer-based instruction agree that effective interactivity requires the learner to be in control of the pace of the presentation [28], [29], and past research has shown that, on measures of transfer, learners who are allowed to exercise control over the pace of a multimedia message out perform those who are not [30].

\subsection{Technology for cognition}

The primary motivation for integrating ICT in education is this belief that it supports students in their own constructive thinking, allows them to transcend their cognitive limitations, and engages them in cognitive operations that they may not have been capable of otherwise [31].

\subsection{Higher order thinking}

ICT makes for higher-order thinking skills which are "goal-directed, multi-step, strategic processes such as designing, decision making, and problem solving" that require analyzing, evaluating, connecting, imagining, elaborating, and synthesizing [32], and engagement which entails mindfulness, cognitive effort, and attention of the students in the learning environment [33].

\subsection{ICT for livening the class}

Information and communications technology (ICT), is believed to have the potential of livening the classroom environment by making teaching and learning more dynamic, interactive, and innovative [34]. Furthermore, it offers scope for the development of the creative mind, both for the teacher and the student. Computer screens are clearly more graphic or visual and interactive than traditional media, leading the user to scan visual fields, perceive and interact with icons and graphics, and use devices, such as a mouse, to interact with desired material and fields [35].

\subsection{Meeting the learning styles}

Educational multimedia are believed to provide enhanced learning facility and cater to the specific needs of individual users [36]. Besides, multimedia can help in addressing the problem of the mismatch of learning styles [37]. Research studies have shown that students retain $20 \%$ of what they see, $30 \%$ of what they hear, $50 \%$ of what they see and hear, and $80 \%$ of what they see, hear, and interact with [38].

\subsection{Zones of proximal development}

Based on Vygotsky's theory of learning development, frameworks for thinking are offered, not only about how students learn and construct knowledge in social contexts but how teachers (and peers) can scaffold that learning [39], [40]. Teachers assist learners in their zones of proximal development through modeling, feedback, reinforcement, questioning, task structuring, and direct instruction. These supports are continually adjusted, faded, and eventually withdrawn as students move toward expertise, a process that is best facilitated by e-Learning.

\subsection{Offer of cognitive help}

A number of cognitive help giving behaviors include: acknowledgement, questioning, direct instruction, use of examples, praise, task structuring, elaboration seeking, pushing for exploration, and dialogue prompting [41], [42]. In F2F behaviors, for example: praise, using humor, maintaining physical proximity, making eye contact are related positively to student learning [43], [44]. Instructors in online classes use a variety of immediacy behaviors to make up for their lack of physical closeness to students [45]. A study of instructors in three different types of media settings: text-based, audio, and video, find that instructors in each of these settings use immediacy behaviors that are appropriate to their particular medium. The text-based instructors use praise and personal examples, the audio instructors use first names, questioning, humor, and digressions; while video instructors use gestures, smiles, a relaxed posture, and movement around the classroom.

\section{Need for interactive learning environment}

To sufficiently engage students in active learning and encourage sufficiently strong mental effort in an e-Learning environment, educators attempt to stimulate and sustain student motivation through the design of effective interactions [46]. Some interactive programs accessible via the internet may initially attract students' 
attention because of unique screen designs or the inclusion of features such as animation and sounds, but unless the interactions are designed to be cognitively engaging, students will become disenchanted and unmotivated [47].

Many studies of the relationship between motivation and learning achievement confirm that when students are more engaged in learning, they more fully understand new knowledge and are more flexible in their use of it [48]. Levels of engagement are estimated from indirect indicators such as the amount of participation in academic work, the intensity of student concentration, the enthusiasm and interest expressed, and the degree of care shown in completing the work [49].

In e-learning, students do not learn in the systematic way that is implicit in the careful design and structuring of a learning package. Instead they engage with material in different sequences, and are selective in their reading and interactions [50]. The teacher has a pivotal role to play in the ICT-mediated learning environment for students to be engaged in higher-order thinking activities [51]. Some of these roles involve evaluating the ICT tools for their opportunities and limitations,, assessing ICT competencies of students, setting clear expectations, negotiating objectives with students, preparing students for lessons with advance organizers, varying degree of support for different students with customized worksheets or engaging them in dialogues, fading support as students develop learner autonomy, and employing tools to encourage reflection on learning activities.

The strategies for integration of intrinsic motivational factors into software design include: challenge, control, curiosity, and fantasy, and help to engage the learner [52]. Situational interest, which is elicited by content or context rather than by personal preferences, is more important than personal interest in the classroom because the teacher can rarely impact a student's personal interests [53].

\section{VI. e-learning is more effective}

Access to technology is critical, as shown when in 'laptop classes' for grades 5-7, there was greater use of student-centered teaching strategies, such as project-based learning, independent inquiry, teacher as coach, and cooperative learning. These classes were busier and more active learning environments. Most revealing was the laptop students' superiority in using the computer as a learning tool [54].

The summarized findings from 12 separate meta-analyses assessed the results of over 300 studies, comparing computer-assisted learning with conventional teaching in a variety of instructional settings [55]. The pooled results suggested that students working with computer-based instruction in the 1980s performed slightly but significantly, better overall than did students receiving traditional teaching.

Similar results were reported by another meta-analysis of a further 120 studies published between 1987 and 1992 [56]. Here, the effects of learning with computer-assisted instruction appeared to be greatest with preschool and kindergarten children, followed by learners with special needs. After this, the gains were more modest with elementary school, high school, college and university students and students in adult training situations. Again, results were reported in a summary of 17 early meta-analytic studies covering over 600 such comparison studies in a variety of different disciplines [57]. In the studies stronger gains in subjects like science and mathematics were detected than in literacy. In conclusion, the overall findings constitute very strong evidence in favor of the hypothesis: greater ICT experience is strongly associated with superior performance in public examinations[58].

\section{Parameters for the pilot study}

The Pilot Study was undertaken in a private educational institute, in an urban location, offering a National Board of Examination, where the medium of instruction was English, and the subjects were familiar with working on the computer, especially with power-point slides. The subjects were from class six, with ages ranging from 11 to 13 . They were randomly assigned to two distinct groups with 22 subjects for Online learning $(\mathrm{ON})$ with 42 subjects for Face-to-Face learning (F2F). For purposes of this study, they were divided into above average and below average groups, based on their school performance in the final term examination.

\subsection{Small numbers working online (ON)}

As all the subjects were only available for a very limited time period, the $\mathrm{ON}$ and F2F learning had to take place simultaneously. There were constraints with only one computer laboratory being available, which had a limited number of computers working. In the ON learning, the subjects were expected to work individually on a computer, though they could move around and seek help from their peers or the instructor present.

\subsection{Other factors kept in mind}

The subject matter covered was the topic on 'Percentages', which included getting to know the concept of 'percentages', and then being able to calculate 'percentages' in given situations. It also dealt with relating the topic of 'fractions' and 'decimals' to 'percentages'. The number of slides for the topic did not exceed 35, for 
each segment keeping in mind the cognitive load of the subject-matter being learnt. The study material was presented in a step-by-step manner, on the lines of Worked Examples, as distinct from Practice Problems. In addition to the study slides, there were hyperlinked slides that offered the subjects assistance, feedback and acknowledgement of their performance.

\subsection{The pilot study hoped to examine}

In the pilot study, given the exposure to colorful power-point presentations, with a male and female voice over, there were two hypothesis. H1: There is no difference in post-test scores attained, when exposed to either F2F or ON mode of learning. H2: There is no difference in the post-test scores attained, by subjects below median, when exposed to either F2F or ON mode of learning.

\section{Method}

The entire group was given a pre-test based on the matter to be learnt before they could split up, with some going to the computer laboratory for the ON, while others stayed on in the audio-video room for the F2F. In the ON mode, the subjects accessed the study material on the computer as power point slides, the pace of which they could control. While in the F2F, the instructor presented identical material on a big screen for the students to grasp, pausing to clear doubts, or to check the pace of their progress. Both groups were given a short break, between two sessions of learning so as to prevent a cognitive overload. When the two groups finished the learning activities, they were given a post-test on the material learnt.

\section{Findings}

Comparing the mean of the pre-test and post-test scores of the 64 subjects, the mean score for pre-test in face-to-face (F2F) learning was 18.02, while its post-test score was 23.21. On the other hand, the mean score for the pre-test in online $(\mathrm{ON})$ learning was 21.25, while its post-test score was 25.23, as depicted in Fig.1.

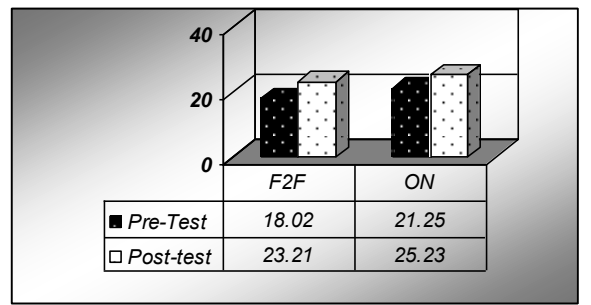

Figure 1. Mean scores for F2F and ON

An independent $t$-test was conducted comparing the post-test scores of F2F and ON group. A significant difference was found $(t(62)=.054, p<.05)$ with the ON group scoring higher $(M=25.23, s=5.33)$ than the F2F group $(M=23.21, s=8.72)$. The details are show in Table 1. Thus rejecting H1: There is no difference in post-test scores attained, when exposed either F2F or ON mode of learning. The ON mode of learning is more effective than F2F mode of learning.

Table 1 Post Tests of (F2F) and (ON)

\begin{tabular}{|c|c|c|c|} 
& $\mathrm{N}$ & Mean & $\mathrm{SD}$ \\
\hline $\begin{array}{c}\text { Face to Face } \\
\text { (F2F) }\end{array}$ & 42 & 23.21 & 8.72 \\
\hline Online (ON) & 22 & 25.23 & 5.33 \\
\hline
\end{tabular}

Using the school performance as an objective tool, the subjects were divided by the median score. An independent $t$-test was conducted comparing the post-test of below median scores for F2F and ON group. A significant difference was found $(t(22)=.281, p<.05)$ with the ON group scoring higher $(M=23.00, s=5.55)$ than the F2F group $(M=18.00, s=9.59)$. The details are shown in Table 2. Thus rejecting H2: There is no difference in the post-test scores attained, by subjects below median, when exposed to ON mode of learning. The ON mode of learning is more effective than F2F mode of learning, for subjects below median scores.

Table 2 Post Tests of Below Median Scores

\begin{tabular}{|c|c|c|c|} 
& $\mathrm{N}$ & Mean & $\mathrm{SD}$ \\
\hline $\begin{array}{c}\text { Face to Face } \\
\text { (F2F) }\end{array}$ & 15 & 18 & 9.59 \\
\hline Online (ON) & 9 & 23 & 5.54 \\
\hline
\end{tabular}




\section{Discussion}

Given the limitations of the software being used for the pilot study, there is greater engagement of the subjects in the ON mode of learning. They can control their pace of learning, as different from all the students having to work at the same pace with the instructor in the F2F learning. In the ON mode, they revisit the previous learning, especially if they are not sure about the matter being taught. The results show that ICT is used effectively in elementary education, with teachers using motivating and informative multimedia. While the content is the same, the mode of delivery $(\mathrm{ON})$ and $(\mathrm{F} 2 \mathrm{~F})$, accounts for the difference in performance.

It is encouraging to see that e-Learning, can deliver better for subjects that are below the median score. Perhaps, this is true in this pilot study, because it deals with mathematics, and maybe due to Worked Examples being used, which are more effective for novices. Hence the ON mode, needs to be studied for other course content too.

\section{Limitations of the research}

The size of the ON group was about half that of the F2F group and that need to be increased for future studies. It would be better to space out the study, rather than trying to do the two sessions in the same day, to avoid unnecessary cognitive load. There were constraints by the number of computers in a laboratory with sound cards and earphones. The ON environment would have been more effective, if the subjects had to feed the answers on the computer rather than on paper.

\section{Conclusion}

The e-Learning really reflects features of 'learning spaces', since it is flexible in nature, bold to go beyond tried and tested pedagogies, and supportive to develop the potential of all learners, especially the subjects below average scores. The processing of the information is certainly handled cognitively, with two separate subsystems, by way of verbal and non-verbal codes. In the e-Learning, the learner has greater access to either of the codes. Hence, despite the limitations of the computer-mediated communication offered in this pilot study, e-learning points a definite way forward.

In many countries, priority has to be given to battling poverty and food shortages before educational needs [59]. However, the Indian Government, while not brushing aside the issues of poverty and food shortages, does see education as a key ingredient to economic development and prosperity for all.

\section{Acknowledgement}

This pilot study is partly supported by UGC-UPE II, for the Cognitive Science Project, in the School of Cognitive Science, Jadavpur University, Kolkata (India).

A special thanks to Principals of St. Joseph's College and St. Mary's School, their staff and subjects who willingly participated or offered the infrastructure for the pilot study.

\section{References}

[1] J. Dewey, Experience and education (New York: Collier Macmillan, 1938)

[2] I. Jung, and C. Latchem, A model for e-education: Extended teaching spaces and extended learning spaces. British Journal of Educational Technology, Vol 42 No 1, 2011, pp. 6-18.

[3] A. Gunasekaran, R.D. McNeil, and D. Shaul, E-learning: research and applications. Industrial and Commercial Training, 34, 2, 2002, 44-53.

[4] S. Alexander, E-learning developments and experiences. Education \& Training, 43, 4/5, 2001, $240-248$.

[5] A. Bork, Personal computers for education (New York: Harper \& Row, 1985).

[6] A. Bain, and K. Ross, School reengineering and SAT-1 performance: A case study. International Journal of Education Reform, 9(2), $1999,148-153$.

[7] CEO Forum on Education and Technology, The CEO Forum school technology and readiness report: Key building blocks for student achievement in the 21st century (2001). Retrieved May 10, 2006 from http://www.ceoforum.org/downloads/report4.pdf.

[8] J. Sivin-Kachala, and E.R. Bialo, Research report on the effectiveness of technology in schools, 2000, Washington, DC: Software and Information Industry Association.

[9] C.J. Bonk, and K. Zhang, Empowering online learning: 100+ activities for reading, reflecting, displaying, and doing. (San Francisco: Jossey-Bass, 2008).

[10] D.H. Jonassen, J.Howland, and R.M. Marra, Meaningful learning with technology, $3^{\text {rd }}$ Ed., (Columbus, OH: Merrill/Prentice Hall, 2007).

[11] P. Freire, Pedagogy of the oppressed (New York: Continuum, 1970).

[12] J. Bruner, Toward a theory of instruction (Cambridge, MA: Harvard University Press, 1966).

[13] T.M. Duffy, and D. Jonassen, Constructivism and the technology of instruction: a conversation (Hillsdale, NJ: Lawrence Erlbaum Associates, 1992).

[14] P.A. Ertmer, Addressing first- and second-order barriers to change: Strategies for technology integration. Educational Technology Research and Development, 47(4), 1999, 47-61.

[15] K.F. Hew, and T. Brush, Integrating technology into K-12 teaching and learning: current knowledge gaps and recommendations for future research. Education Tech Research Dev, 55, 2007, 223-252.

[16] J.R. Hill, and M.J. Hannafin, Teaching and Learning in Digital Environments: The Resurgence of Resource-Based Learning. Educational Technology Research and Development, Vol. 49, No. 3, 2001, pp. 37-52. 
[17] M.J. Hannafin, J.R. Hill, and S.M. Land, Student-centered learning and interactive multimedia: Status, issues, and implications. Contemporary Education, 68(2), 1997, 94-99.

[18] P. Freire, Pedagogy of the oppressed: New revised 20th anniversary edition. (New York: Continuum, 1993).

[19] C.M. Reigeluth, and K. Squire, Emerging work on the new paradigm of instructional theories. Educational Technology, 38 (4), 1998, 41-47.

[20] W.E.Segall, and A.E. Wilson, (1998). Learning and teaching in the classroom, in W.E. Segall and A.E. Wilson, Introduction to education: Teaching in a diverse society, (Upper Saddle River, NJ: Merrill, 1998) 151-170.

[21] J.R. Hill, A conceptual framework for under-standing information seeking in open-ended information systems. Educational Technology Research and Development, 47 (1),1999a, 5-28.

[22] D, Chandler, (1999). Semiotics for beginners [online]. Available:http://www.argyroneta.com/s4b/.

[23] R.E. Mayer, and R. Moreno, Nine ways to reduce cognitive load in multimedia learning. Educational Psychologist, 38, $2003,43-52$.

[24] J.M. Clark, and A. Paivio, Dual coding theory and education. Educational Psychology Review, 3, $1991,149-210$.

[25] R. Moreno, and A. Valdez, Cognitive Load and Learning Effects of Having Students Organize Pictures and Words in Multimedia Environments: The Role of Student Interactivity and Feedback. Education Technology Research \& Development, Vol. 53, No. 3, 2005, pp. 35-45.

[26] S. Kalyuga, P. Chandler, and J. Sweller, Managing split-attention and redundancy in multimedia instruction. Applied Cognitive Psychology, 13, 1999, 351-371.

[27] J.J.G. van Merriënboer, and P. Ayres, Research on cognitive load theory and its design implications for e-learning. [This special issue]. Educational Technology Research and Development, 53 (3), 2005, 5-13.

[28] S. Cairncross, and M. Mannion, Interactive multimedia and learning: Realizing the benefits. Innovation in Education and Teaching International, 38(2), 2001, 156-164.

[29] N.A. Stanton, L. J. Porter, and R. Stroud, Bored with point and click? Theoretical perspectives on designing learning environments. Innovation in Education and Teaching International, 38(2), 2001, 175-182.

[30] R.E. Mayer, and P, Chandler, When learning is just a click away: Does simple user interaction foster deeper understanding of multimedia messages? Journal of Educational Psychology, 93, 2001, 390-397.

[31] G. Salomon, No distribution without individuals' cognition, in G. Salomon (Ed.), Distributed cognitions: Psychological and educational considerations, (New York: Cambridge University Press, 1993) 111-138).

[32] Iowa Department of Education. A guide to developing higher-order thinking across the curriculum. Des Moines, IA (ERIC Document Reproduction Service No. ED306 550, 1989, p.7).

[33] G. Kearsley, and B. Shneiderman, Engagement theory: A framework for technology-based teaching and learning. Educational Technology, September-October, 1998, 20-23.

[34] D.C. Naik, and V. Teelock, Enhancing the Teaching and Learning of History and Geography through Information and Communications Technology: A Mauritian Experience. Educational Technology Research and Development. Vol.54, Issue 4, 2006, $422-434$.

[35] D. Kellner, New media and new literacies: Reconstructing education for the new millennium. [online]. http://www.gseis.ucla.edu/courses/ed253a/kellner/newmedia.html, 2000.

[36] D.M. Kennedy, and C. McNaught, Principles of good teaching and interactive multimedia design. [online] http://ultibase.rmit.edu.au/Articles/dec97/kenne1.html, 1997.

[37] L.C. Sarasin, Learning styles perspectives: Impact in the classroom (Madison, WI: Atwood Publishing, 1999).

[38] G.B. Shelly, G.A. Waggoner, T.J. Cashman, and W.C. Waggoner, Discovering computers 98: A link to the future (Boston: Course Technology, Inc, 1998, September).

[39] R.G. Tharp, and R. Gallimore, A theory of teaching as assisted performance, in P. Light, S. Sheldon, and M. Woodhead (Eds.), Learning to think: Child development in social context, Vol. 2, (London: Routledge, 1991) 42-61.

[40] A. Collins, J.S. Brown, and S.E. Newman, Cognitive apprenticeship: Teaching the craft of reading, writing, and mathematics, in L. B. Resnick (Ed.), Knowing, learning, and instruction: Essays in honor of Robert Glaser, (Hillsdale, NJ: Erlbaum, 1990$) 453-494$.

[41] C.J. Bonk, and D.J. Cunningham, Searching for learner-centered, constructivist, and socio cultural components of collaborative educational learning tools, in C. J. Bonk and K. S. King (Eds.), Electronic collaborators: Learner-centered technologies for literacy, apprenticeship, and discourse, (Mahwah, NJ: Erlbaum, 1998) 25-50.

[42] C.J. Bonk, N. Hara, V. Dessen, S. Malikowski, and L. Supplee, We're in TITLE to dream: Envisioning a community of practice, 'The Intraplanetary Teacher Learning Exchange.'. Cyber psychology \& Behavior, 3, 2000, 25-39, doi:10.1089/109493100316201.

[43] D. Christophel, The relationship among teacher immediacy behaviors, student motivation, and learning. Communication Education, 39(4), 1990, 323-340.

[44] M. Weiner, and A. Mehrabian, Language within language: Immediacy, a channel in verbal communication (New York: AppletonCentury-Crofts, 1968).

[45] R. LaRose, and P. Whitten, Re-thinking instructional immediacy for Web courses: A social cognitive exploration. Communication Education, 49(4), 2000, 320-338.

[46] T.C. Reeves, and P.M. Reeves, The effective dimensions of interactive learning on the www, in B. H. Khan (Ed.), Web-based instruction, (Englewood Cliffs, NJ: Educational Technology Publications, 1997) 59-66.

[47] S.P. Lajoie, Computers as cognitive tools: no more walls, 2 (Mahwah, NJ: Lawrence Erlbaum Associates, 2000).

[48] C.S. Rigby, E.L. Deci, B.C. Patrick, and R.M. Ryan, Beyond the intrinsic-extrinsic dichotomy: Self-determination in motivation and learning. Motivation and Emotion, 16(3), 1992, 165-185.

[49] F.M. Newmann, Student engagement and achievement in American secondary schools (New York: Teachers College Press, 1992).

[50] J. Gilbert, S. Morton, and J. Rowley, e-Learning: The student experience. British Journal of Educational Technology Vol 38 No 4, 2007, 560-573.

[51] C.P. Lim, Effective integration of ICT in Singapore schools: pedagogical and policy implications. Education Tech Research Dev, 55, 2007, 83-116.

[52] S-K. Wang, and T.C. Reeves, The effects of a web-based learning environment on student motivation in a high school earth science course. Education Technology Research and Development, 55, 2007, 169-192.

[53] D.A. Bergin, (1999). Influences on classroom interest. Educational Psychologist, 34(2), 1999, 87-98.

[54] D.L. Lowther, S.M. Ross, and G.M. Morrison, When Each One Has One: The Influences on Teaching Strategies and Student Achievement of Using Laptops in the Classroom. Educational Technology Research \&Development. Vol. 51, No. 3, (2003), 23-44.

[55] M.W. Lipsey, and D.B. Wilson, The efficacy of psychological, educational, and behavioral treatment: confirmation from metaanalysis. American Journal of Psychology, 48, 12, 1993, 1181- 1209. 
[56] C.M. Fletcher-Flinn, and B. Gravatt, The efficacy of computer-based instruction (CAI): a meta-analysis. Journal of Educational Computing Research, 12, 3, 1995, 219-242.

[57] J.M. Parr, A review of the literature on computer-assisted learning, particularly integrated learning systems, and outcomes with respect to literacy and numeracy (Updated October 10, 2005). Retrieved November 11, 2005, from http://www.minedu.govt.nz/index.cfm?layoutdocument\&documentid5499\&CFID. 2005.

[58] C. Harrison, E.A. Lunzer, P. Tymms, C. Taylor Fitz-Gibbon, and J. Restorick, Use of ICT and its relationship with performance in examinations: a comparison of the ImpaCT2 project's research findings using pupil-level, school-level and multilevel modeling data. Journal of Computer Assisted Learning, 20, 2004, 319-337.

[59] J. Hartley, Teaching, learning and new technology: a review for teachers. British Journal of Educational Technology, Vol. 38, No 1, 2007, 42-62. 